Document downloaded from:

http://hdl.handle.net/10251/99468

This paper must be cited as:

Sapena-Bano, A.; Manuel Pineda-Sanchez; Rubén Puche-Panadero; Martinez-Roman, J.; Kanovic, Z. (2015). Low-Cost Diagnosis of Rotor Asymmetries in Induction Machines Working at a Very Low Slip Using the Reduced Envelope of the Stator Current. IEEE Transactions on Energy Conversion. 30(4):1409-1419. doi:10.1109/TEC.2015.2445216

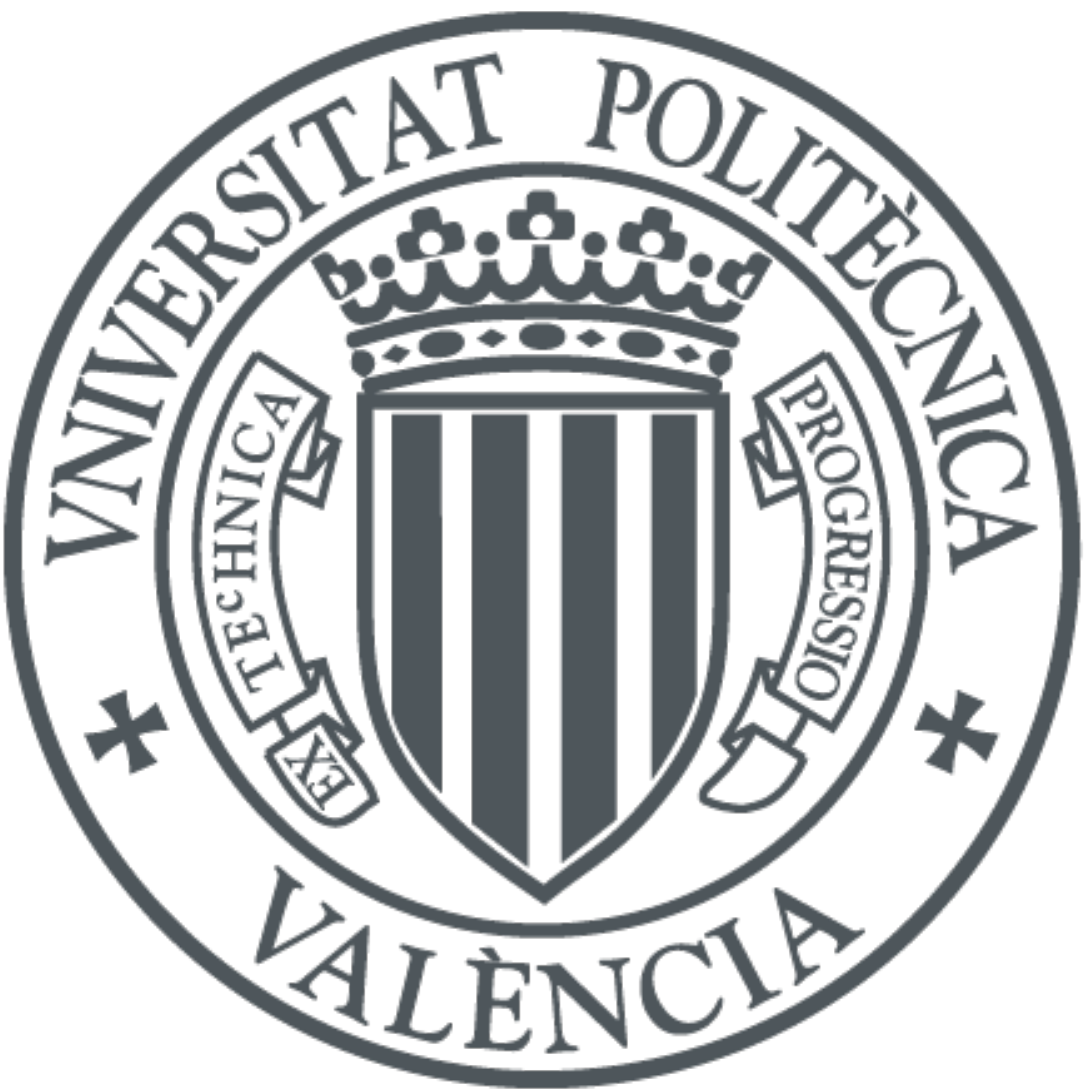

The final publication is available at

http://doi.org/10.1109/TEC.2015.2445216

Copyright Institute of Electrical and Electronics Engineers

Additional Information 


\title{
Low Cost Diagnosis of Rotor Asymmetries in Induction Machines Working at a Very Low Slip, Using the Reduced Envelope of the Stator Current
}

\author{
A. Sapena-Baño, M. Pineda-Sanchez, Member, IEEE, R. Puche-Panadero, Member, IEEE, J. Martinez-Roman, \\ and Ž. Kanović, Member, IEEE.
}

\begin{abstract}
Fault diagnosis of rotor asymmetries in induction machines working at a very low slip, through Fourier based methods, usually requires a long acquisition time, to achieve a high spectral resolution, and a high sampling frequency, to reduce aliasing effects. However, this approach generates a huge amount of data, which difficult its implementation using embedded devices with small internal memory, such as digital signal processors (DSPs) and field programmable gate arrays (FPGAs), or devices with low computing power. In this paper, a new simplified diagnostic signal, designated as the reduced envelope of the stator current, is introduced to address this problem. The reduced envelope signal is built using only one sample of the current per cycle, without any further processing, and it is demonstrated that it carries the same spectral information about the fault than the full-length current signal. Based on this approach, an embedded device has only to store and process a minimal set of samples, compared with the raw current signal, for a desired resolution. In this paper the theoretical basis of the proposed method is presented, as well as its experimental validation using two different motors with broken bars: a high power induction motor working in a factory and a low power induction motor mounted in a laboratory test bed.
\end{abstract}

Index Terms-Induction motor, Fault diagnosis, Hilbert transforms, Fourier transforms, Condition monitoring, Motorcurrent signature analysis, Broken rotor bar detection, Fieldprogrammable gate array (FPGA), Digital signal processor (DSP), Signal processing.

\section{INTRODUCTION}

$\mathbf{I}$ NDUCTION machines (IMs) are a key component of modern industrial processes, and their failures may cause extremely heavy losses, so there is a rising interest in on-line diagnostic methods, which can detect a machine fault without disturbing its normal operation. Motor current signature analysis (MCSA) has become the reference method for the fault diagnosis of IMs. It is a non-invasive method, requiring just a current sensor to capture the stator current, and it can identify a wide variety of machine faults through the analysis of the current spectrum, which can be computed through the fast Fourier transform (FFT).

This work was supported by the Spanish "Ministerío de Economía y Competitividad" in the framework of the "Programa Estatal de Investigación, Desarrollo e Innovación Orientada a los Retos de la Sociedad" (project reference DPI2014-60881-R). A. Sapena-Baño (ansaba2@upvnet.upv.es), M. PinedaSanchez (mpineda@die.upv.es), R. Puche-Panadero (rupucpa@die.upv.es), and J. Martinez-Roman (jmroman@die.upv.es) are with the Department of Electrical Engineering, Universitat Politècnica de València, Camino de Vera s/n, 46022, Valencia, Spain. Ž. Kanović (kanovic@uns.ac.rs) is with the Department of Computing and Control Department, University of Novi Sad, Serbia.
From an industrial point of view, MCSA faces practical difficulties, such as:

- The spectral leakage of the mains component may hide the fault harmonics, with much lower amplitude, specially if their frequency is close to the main frequency of the power supply ( $\left.f_{\text {mains }}\right)$. This is the case of rotor asymmetries faults in motors working at a very low slip, either large motors with a very low rated slip, or any motor tested unloaded [1]. The $f_{\text {mains }}$ component can be eliminated with notch filters [2], wavelet filters [3], [4], shifting it to a DC value [5]-[7], or using a time-domain approach, like the zero crossings times (ZCT) [8], [9], or the quad-demodulation [10] methods.

- Spectral resolution must be high enough to properly resolve and identify the fault harmonics among a miriad of spectral lines that appear in the current spectrum [11], even in the case of a healthy machine [12]. A high spectral resolution of $0.01 \mathrm{~Hz}$ has been reported as necessary to precisely identify the broken bar fault harmonics of motors working at a very low slip in [6], [7], [13]. Such a high resolution has been achieved either by using a standard FFT with a long sampling time (100 seconds in [6], [13], [14]), or by concentrating only in the detection of the expected fault frequencies [15]. A reduction of the sampling time, while maintaining the spectral resolution, has been reported using Zoom-FFT [13], MUSIC [16], or ESPRIT [7], [17], [18] methods, although they have high computational requirements.

- The sampling rate must be high enough to reduce aliasing artifacts in the spectrum, specially if the machine is fed from a variable speed drive (VSD) [19]. Low sampling rates can be used if the current is smoothed with analog anti-aliasing filters, as in [1], [2], [9], [20]-[22]. Nevertheless, a growing trend consists in sampling the current at a very high rate, and applying a low pass digital filter to the sampled signal. Modern low cost hardware devices can operate at sampling rates above $100 \mathrm{kHz}$ [19], with digital filtering, so that high sampling rates are being increasingly used: $20 \mathrm{kHz}$ in [23], $50 \mathrm{kHz}$ in [24], and $100 \mathrm{kHz}$ in [25].

- MCSA methods can be computationally expensive, but the diagnostic procedures must be simple, compact and fast, to be executed on line by embedded devices [2], [26] such as DSPs [1], [15], [20], FPGAs [21], [27], portable 
devices [9], [28], small wireless sensors [24], low cost processors [29], or energy-constrained sensor modules [30]. A growing trend is to implement the diagnostic algorithms in the same device that controls the power electronics in VSDs [31], [32], so it is imperative to keep the use of resources as low as possible in order to not disturb the normal operation of the controller.

Some of these requirements are conflicting ones. A high spectral resolution requires a long acquisition time, and combined with a high sampling rate generates a huge amount of data to be stored and processed, which implies buffering, large size memory and high computing power, that is, costly devices. As [15] states, these requirements bring an overwhelming burden to a DSP.

On the other hand, in recent years, a number of methods based on the analysis of the current envelope have been developed [4], [6], [7], [33]-[37], aiming to fix the problems discussed above. As shown in [6], [7], [33], the current envelope contains the same harmonics than the current wave, but shifted in the frequency domain, in such a way that the mains component is converted into a DC component, regardless the value of supply frequency $f_{\text {mains }}$. In this way, the masking effect of the fundamental component can be eliminated, using different techniques. In [6] the mains component is eliminated by simply subtracting from the current envelope its average value, demonstrating that this technique enables the detection of broken bars at very low slip. In [4] the discrete wavelet transform (DWT) is applied to the squared instantaneous amplitude of the stator current, obtained as the amplitude of the Hilbert transform (HT) of the phase current. The fault component is detected through an increase of the energy in the wavelet signal whose bandwidth contains the frequency of the fault component, taking profit of the increased resolution of the DWT at low frequencies. The authors emphasize that this method does not require slip estimation. A different approach is proposed in [33], where the empirical mode decomposition (EMD) is used for isolating the mains component, which is extracted as the intrinsic mode function 1 (IMF1), from the fault components, which are included in the IMF2 for direct on line supplied machines, or in the IMF3 in the case of inverted feed machines. Once the fault component is isolated, the fault is detected through the evaluation of the amplitude of the envelope of the IMF2 or the IMF3.

Besides, the current envelope has also been used in expert systems approaches, based on artificial intelligence techniques, as in [35], [36]. In [35], the concept of three-phase currents envelope is introduced. This envelope is extracted from the stator currents through a process consisting of four steps (low pass filtering, extraction of the positive peaks of the currents, interpolation and normalization). Once the envelope is built, it is used in conjunction with artificial intelligence (AI) techniques to isolate the motor faults. In [36], the performance of different classifiers for detecting faults is studied, using features extracted from the current envelope as inputs, and the results are compared with those obtained using conventional features of the current signal. The authors claim that the use of features extracted from the current envelope leads to more accurate diagnostic systems.
The above commented approaches are examples that illustrate the potential of using the current envelope in the diagnostic field. Nevertheless, obtaining the current envelope is costly in terms of computer resources. First, a complex signal, the analytic signal (AS), must be constructed using the Hilbert transform of the stator current [4]-[7], [20], [37], and, second, the modulus of this signal (the current's envelope) must be computed for every sample of the current.

This paper introduces a new approach, based on the analysis of a new signal, designated as the reduced envelope of the stator current. It is demonstrated that this signal can be used for the diagnosis of rotor asymmetries at very low slip, as in [4], [6], [7], keeping the good sensitivity and frequency resolution demonstrated by these approaches. But unlike the conventional envelope used in these works, the reduced envelope proposed in this paper is built using just one sample per cycle of the stator current, and without computing the modulus of the AS of the current. Both features represent very significant advantages regarding the methods based on the current envelope described in the previous literature. Compared with them, the proposed approach greatly reduces the computational burden in the practical implementation of the current envelope approach, in terms of computation time and memory requirements. This makes the proposed method especially well-suited for implementing envelope based diagnostic approaches on embedded and low cost processors.

The structure of this paper is as follows: in Section II, a case study is presented using a large $3.15 \mathrm{MW}$ motor, with a broken bar, operating at a very low slip. In Section III, the previous approaches for the diagnosis of rotor asymmetries at a very low slip that are the basis of the new proposed approach are explained. In Section IV, the new quantity proposed for the diagnosis of the machines fault is defined and theoretically justified. In Section $\mathrm{V}$, an experimental validation of the proposed method is carried on with a laboratory test rig, using commercial motors fed from VSDs, operating in Constant voltage per frequency $(\mathrm{CV} / \mathrm{F})$ and direct torque control (DTC) mode. In Section VI a comparative analysis between the traditional current envelope and the new signal proposed in this paper, the reduced current envelope, is presented. Finally, Section VII presents the conclusions of this work.

\section{CASE STUdY: HIGH POWER, HIGH VOLTAGE INDUCTION MOTOR WITH BROKEN BARS}

The theoretical development of the proposed method, and its comparison with previous approaches, is illustrated with a case study, a 3.15 MW grid-connected, high-voltage induction motor (see Appendix A, motor type I), which drives a low and a high pressure pumps in a thermal power plant-heating plant. Visual inspection after tests showed that the motor had one broken bar, as shown in Fig. 1. This type of fault generates two characteristic side bands harmonics around the mains frequency component, at frequencies given by

$$
f_{\mathrm{SB}_{-} \text {broken_bar }}=(1 \pm 2 s) f_{\text {mains }}=f_{\text {mains }} \pm f_{\text {broken_bar }} \text {, }
$$

where $f_{\text {broken_bar }}=2 s f_{\text {mains }}$ stands for the characteristic frequency of the broken bar fault, which depends on the slip 
$s$. If the motor operates at a very low slip, the diagnosis of this type of fault is specially challenging, because the fault harmonics are very close to the mains component. This is the case of the motor of Fig. 1, which has been monitored while operating in steady state at a speed of $2995 \mathrm{rpm}\left(f_{\text {mains }}=\right.$ $49.97 \mathrm{~Hz}$ ), with a slip of just $s=0.0011$. The frequency of the fault harmonics (1) is just $f_{\text {broken_bar }}= \pm 0.11 \mathrm{~Hz}$. The current has been acquired during a sampling time $T_{\text {acq }}$ of 100 seconds, to achieve a spectral resolution of $0.01 \mathrm{~Hz}$, with a sampling frequency of $5 \mathrm{kHz}$, which gives a total amount of $5 \times 10^{5}$ samples. The spectrum of this current, calculated through the conventional FFT, is shown in Fig. 2. In spite of the long sampling time and the great amount of values used to compute the spectrum, the fault harmonics are almost completely hidden by the spectral leakage of the mains component.

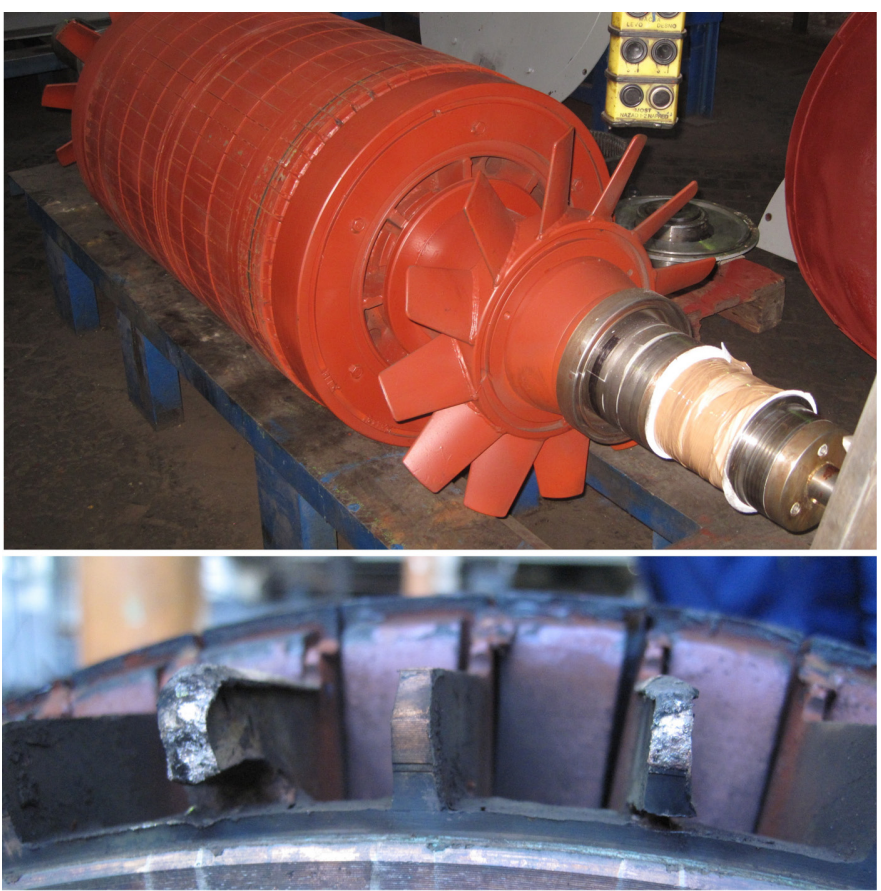

Fig. 1. Top:rotor of the motor of 3.15MW. Bottom: detail of the broken bar

\section{PREVIOUS APPROACHES FOR DIAGNOSING ROTOR ASYMMETRIES AT VERY LOW SLIP}

In this section, two approaches that have been proposed in the literature, and which constitute the basis of the new approach proposed in this work, are commented. Since both approaches rely on the concept of the analytic signal of the current, a first subsection is dedicated to introduce this concept.

\section{A. Analytic signal of the current in a faulty machine}

The stator phase current of a healthy machine can be considered as purely sinusoidal

$$
i_{\text {healthy }}(t)=I_{\mathrm{m}} \cos \left(2 \pi f_{\text {mains }} t\right)=I_{\mathrm{m}} \cos \left(\omega_{\text {mains }} t\right),
$$

where $\omega_{\text {mains }}=2 \pi f_{\text {mains. }}$. In the case of a machine fault, new components associated to the fault appear in the stator current.

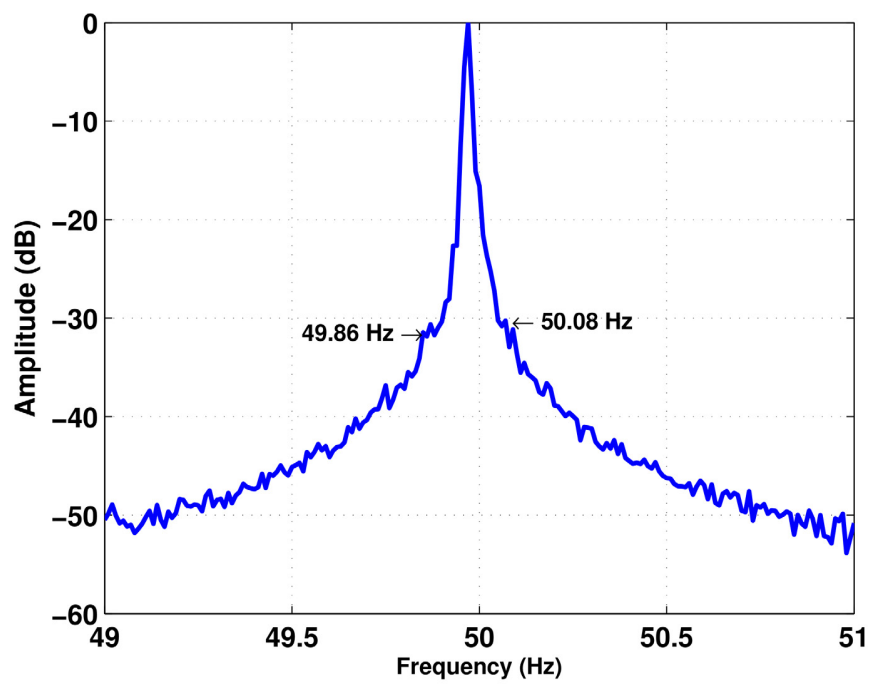

Fig. 2. Spectrum of the current of the $3.15 \mathrm{MW}$ motor with one broken bar. The fault harmonics are hardly visible due to the mains component leakage.

They can be modelled as a modulation of the healthy motor's current [6], as

$$
i_{\text {faulty }}(t)=\left[1+\beta \cos \left(\omega_{\text {fault }} t\right)\right] i_{\text {healthy }}(t),
$$

where $\beta$ is the modulation factor, and $\omega_{\text {fault }}=2 \pi f_{\text {fault }}$ is the characteristic frequency of the fault component, which for a rotor asymmetry is given by $2 s f_{\text {mains }}(1)$.

As the modulation factor $\beta$ in (3) is usually small (less than $1 \%$ in the case of a broken bar), the FFT of (3) is dominated by the mains component, whose leakage can bury fault harmonics that are close to it. To overcome this problem it is advisable to express the current (3) using a complex representation, as

$$
\vec{i}_{\text {faulty }}(t)=A(t) \times e^{j \theta(t)},
$$

so that

$$
i_{\text {faulty }}(t)=\Re\left(\vec{i}_{\text {faulty }}(t)\right) .
$$

That is, the current signal of the faulty machine is the projection onto the real axis of a rotating phasor that has variable amplitude and phase. The expression (4) is not unique, but there exists a canonical representation of (4), the analytic signal (AS). It is built using the Hilbert transform $(\mathcal{H})[6]$ as

$$
\vec{i}_{\text {faulty }}(t)=i_{\text {faulty }}(t)+j \mathcal{H}\left(i_{\text {faulty }}\right)(t),
$$

so that the AS of the stator current of a faulty machine can be expressed as [6]

$$
\vec{i}_{\text {faulty }}(t)=\left[1+\beta \cos \left(\omega_{\text {fault }} t\right)\right] I_{\mathrm{m}} \times e^{j\left(\omega_{\text {mains }} t\right)} .
$$

From (7), $\vec{i}_{\text {faulty }}(t)$ is a phasor rotating at a constant angular speed imposed by the mains' frequency, $\omega_{\text {mains }}$, and a modulus whose value oscillates around its mean value, $I_{\mathrm{m}}$, with a frequency characteristic of each type of fault, $\omega_{\text {fault }}$.

\section{B. Application of the AS of the current to the fault diagnosis of IMs}

Two quantities derived from the AS of the current, $\vec{i}_{\text {faulty }}(t)$ (7), can be used for fault diagnosis of IMs: its modulus, and the shape that this complex quantity draws in a polar diagram. 
1) Fault diagnosis of IMs using the modulus of the AS of the current: As stated in (7), the modulus of the AS of the current oscillates with a frequency characteristic of each type of fault, $\omega_{\text {fault }}$, so it can be used as a diagnostic quantity. This signal is known as the envelope of the current, and it is displayed in Fig. 3 in the case of the 3.15 MW motor.

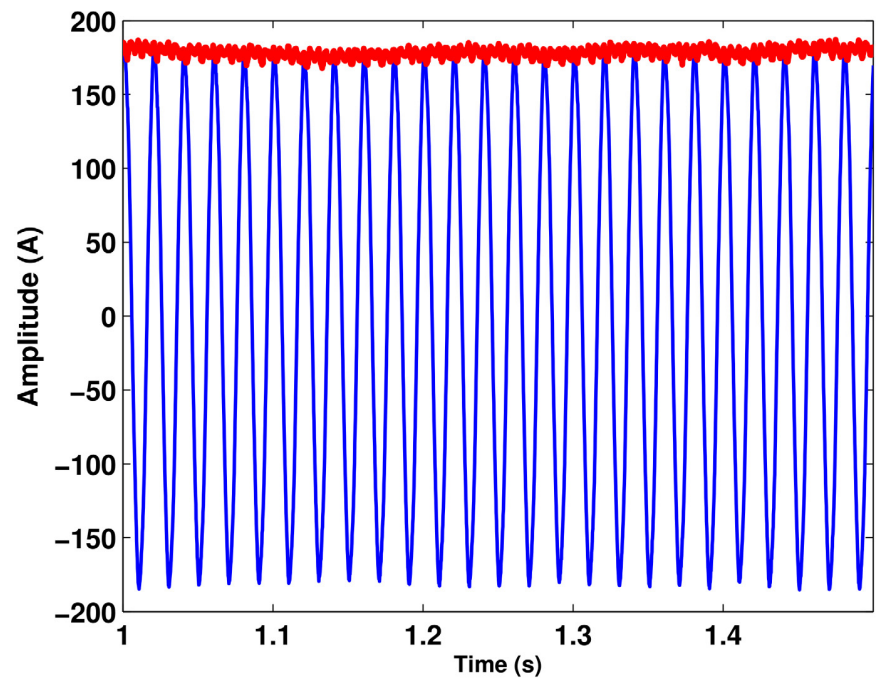

Fig. 3. Current (thin, blue line) of the $3.15 \mathrm{MW}$ motor with one broken bar, $i_{\text {faulty }}$, and its envelope (thick, red line), $\left|\vec{i}_{\text {faulty }}(t)\right|$.

From (6), the envelope of the current can be computed as

$$
\left|\vec{i}_{\text {faulty }}(t)\right|=\sqrt{i_{\text {faulty }}(t)^{2}+\mathcal{H}\left(i_{\text {faulty }}\right)(t)^{2}} .
$$

As it can be seen in Fig. 3, the current envelope has a DC component that is proportional to the mains component. On the contrary, the $\mathrm{AC}$ component of the current envelope

$$
i_{\text {en__faulty }}(t)=\frac{\left|\vec{i}_{\text {faulty }}(t)\right|-\overline{\left|\vec{i}_{\text {faulty }}(t)\right|}}{\mid \overrightarrow{\vec{i}_{\text {faulty }}(t) \mid}},
$$

where $\overline{\left|\vec{i}_{\text {faulty }}(t)\right|}$ is the mean value of $\left|\vec{i}_{\text {faulty }}(t)\right|$, contains all the diagnostic information needed to detect the fault, and it is free from the spectral leakage associated to the mains component [6]. Considering (3) and (7), (9) becomes

$$
i_{\text {env_faulty }}(t)=\beta \cos \left(\omega_{\text {fault }} t\right) \text {. }
$$

Hence, in the spectrum of $i_{\text {env_faulty }}(t)$ (10) the fault harmonics appear at the characteristic frequency of the fault, $\omega_{\text {fault }}$, instead of side bands around the mains' component, which does not appear in this spectrum. This eliminates the problem of the spectral leakage of the mains' component, thus making the fault harmonics more visible. Both features can be observed in the spectrum of the current envelope of the 3.15 MW motor (Fig. 4). The fault harmonics, which in Fig. 2 are hardly visible, appear now so clearly that a linear scale instead of a logarithmic one can be used, improving the spectrum legibility. Moreover, the fault harmonics appear at their characteristic frequency $f_{\text {broken_bar, making it easier }}$ to identify them. And, additionally, multiples of the fault harmonics predicted theoretically can also be detected, which contributes to confirm the diagnosis of the fault.

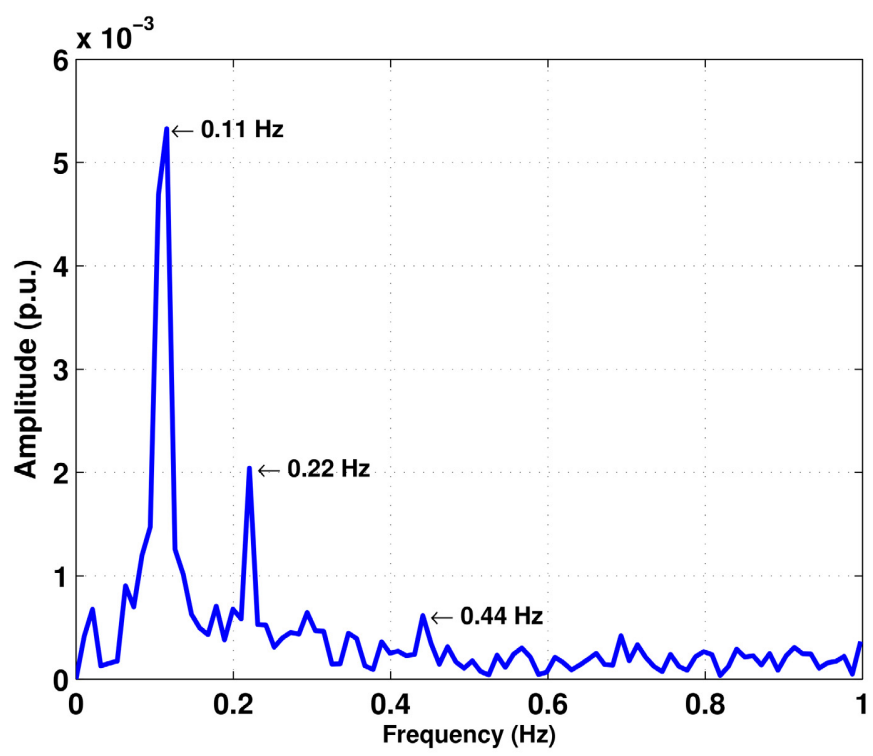

Fig. 4. FFT of the current envelope, $i_{\text {env faulty }}(t)$, of the $3.15 \mathrm{MW}$ motor with one broken bar $\left(5 \times 10^{5}\right.$ data points).

2) Fault diagnosis of IMs using the polar diagram of the AS of the stator current: Another diagnostic approach is to represent the complex quantity $\vec{i}_{\text {faulty }}(t)$ using a polar diagram. If the machine is in healthy condition, this plot is a clean circumference, while in the case of a faulty machine its shape is annular, with a width that is proportional to the modulation factor $\beta$ in (7), as can be seen in Fig. 5.

\section{Proposed methodology: The Reduced enVelope OF THE STATOR CURRENT}

While the two AS-based diagnostic techniques presented in Section III-B1 (the envelope of the stator current), and in Section III-B2 (the polar diagram of the AS of the stator current) can correctly detect and identify the fault, even in the case of IMs operating at a very low slip, they all share the same drawback: the number of sampled data points needed to achieve a high spectral resolution can be very high. In fact, if a frequency $f_{\text {sampling }}$ is used to sample the stator current during a time $T_{\mathrm{acq}}$, the discrete current envelope signal (10) becomes

$$
i_{\text {env_faulty }}[n]=\beta \cos \left(\omega_{\text {fault }} \frac{n}{f_{\text {sampling }}}\right) \quad n=0, \ldots, N_{\text {max }} .
$$

The number of points to be stored in (11) is $N_{\max }=$ $T_{\text {acq }} \times f_{\text {sampling, }}$, which can be very high, specially if the fault harmonics are very close to the mains component and a long acquisition time is required. For example, in the case of the 3.15 MW motor, $N_{\max }=5 \times 10^{5}$ data points. The use of such a huge number of data points to compute the spectrum of the stator current (Fig. 2), the spectrum of the current envelope (Fig. 4), or to generate a polar diagram of the AS of the current (Fig. 5), is a serious obstacle to implement these techniques in low memory components, such as DSPs or FPGAs. Besides, 
(8) must be computed for every sample of the current, which can consume considerable computing resources.

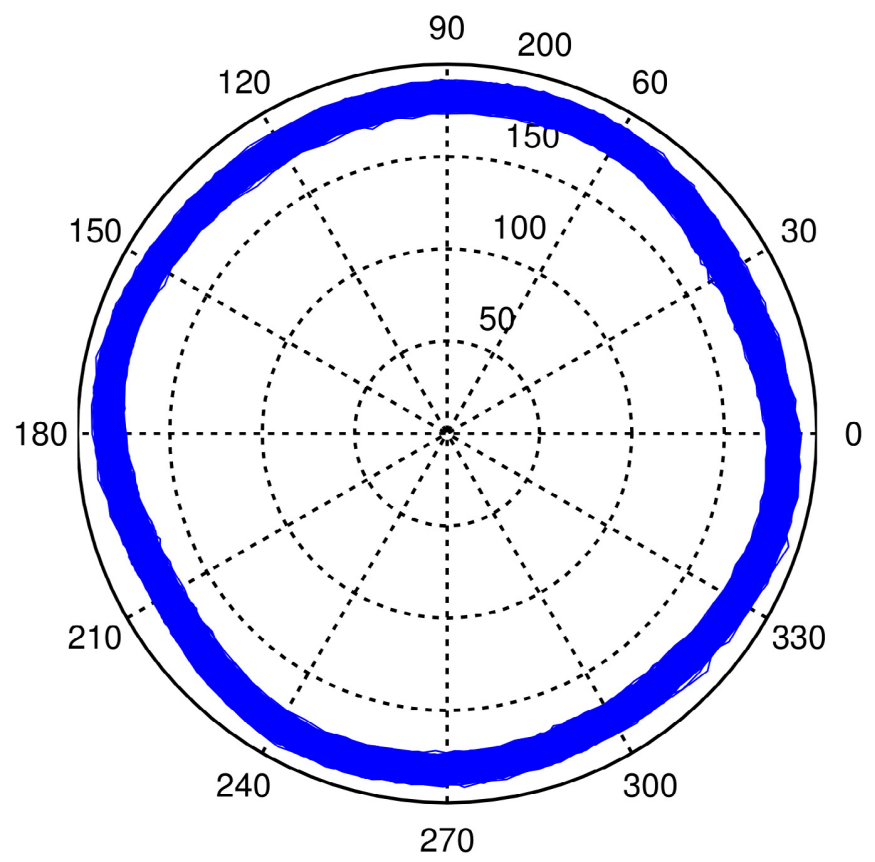

Fig. 5. Polar plot of the AS of the current, $\vec{i}_{\text {faulty }}(t)$, of the $3.15 \mathrm{MW}$ motor with one broken bar.

To overcome both problems, the need of a high computing power and high storage resources, a new diagnostic signal is proposed in this paper, the reduced envelope of the stator current. It is built using a small subset of the samples of the current envelope, (8), obtained at the time points when the angle of the AS in (4) is $\theta(t)=2 k \pi(k=0,1 \ldots)$. At these points the imaginary part of the AS of the current is zero, so from (6), the AS of the current, and hence its envelope, coincides with the instantaneous value of the current itself

$\left|\vec{i}_{\text {faulty }}(t)\right|_{\theta(t)=2 k \pi}=\left|A(t) e^{j \theta(t)}\right|_{\theta(t)=2 k \pi}=\left.i_{\text {faulty }}(t)\right|_{\theta(t)=2 k \pi}$

In this way, by storing the samples of the current given by (12) (just one sample per current cycle), a down sampled envelope of the current is generated, and, at the same time, the computation of the modulus of the AS of the current (8) is completely avoided, because in (12) the modulus of the AS of the current is just the value of the current itself, so no further computation is needed.

The proposed approach has a physical interpretation: if the AS of the current is plotted in a 3D cylindrical coordinates system, using the time as z-axis, then the 2D shape of Fig. 5 changes to a 3D helical shape, shown in Fig. 6. In the proposed approach, instead of using all the values of the current envelope for diagnostic purposes (Fig. 6, solid line), only the samples of this 3D cylindrical representation at the specific angles $\theta(t)=2 k \pi$, with $k=0,1 \ldots$, are used (Fig. 6, dotted line).

In close resemblance with (9), the novel diagnostic quantity proposed in this paper, the reduced envelope of the stator current, $i_{\text {red_env_faulty }}(t)$, is defined as the AC component of

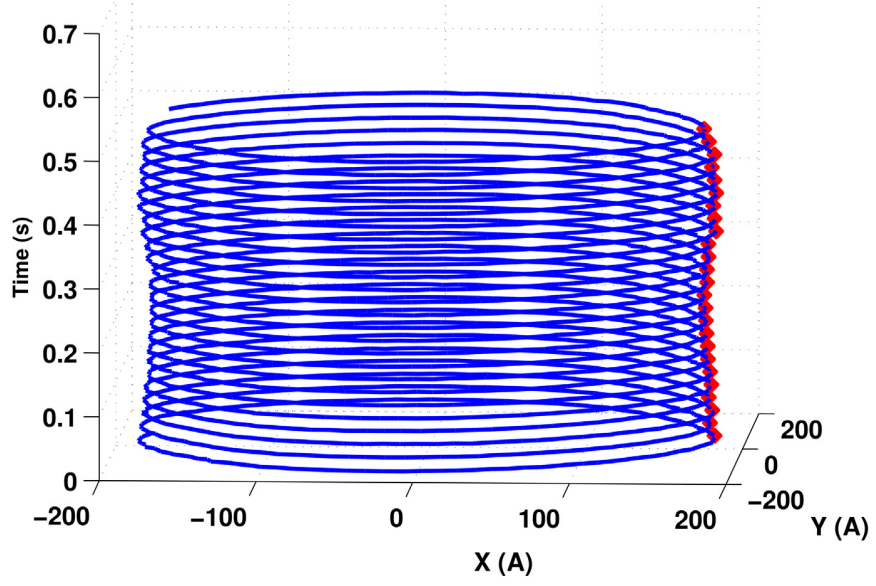

Fig. 6. Physical interpretation of the proposed approach in the case of the 3.15 MW motor with one broken bar. Thin, blue line: cylindrical representation of the current envelope, $\left|\vec{i}_{\text {faulty }}(t)\right|$. Dotted, red line: samples of the current envelope $\left|\vec{i}_{\text {faulty }}(t)\right|_{\theta(t)=2 k \pi}$ used to built the reduced envelope of the current.

(12), properly rescaled,

$i_{\text {red_env_faulty }}(t)=\frac{\left|\vec{i}_{\text {faulty }}(t)\right|_{\theta(t)=2 k \pi}-\left|\vec{i}_{\text {faulty }}(t)\right|_{\theta(t)=2 k \pi}}{\left|\vec{i}_{\text {faulty }}(t)\right|_{\theta(t)=2 k \pi}}$.

In a faulty machine, using (7) and (12), (13) becomes

$$
i_{\text {red_env_faulty }}(t)=\left.\beta \cos \left(\omega_{\text {fault }} t\right)\right|_{\omega_{\text {mains }} t=2 k \pi},
$$

which proves that the spectrum of the new diagnostic signal, $i_{\text {red_env_faulty }}(t)$, contains the fault components, exactly the same that can be found in the spectrum of the full current envelope, $i_{\text {env_faulty }}(t)$ (10), but using a small fraction of the original samples and without the cost associated to the computation of (8).

From (14), the set of samples needed to built the reduced envelope of the current are given by

$$
i_{\text {red_env_faulty }}[k]=\beta \cos \left(\omega_{\text {fault }} \frac{k}{f_{\text {mains }}}\right) \quad k=0, \ldots, k_{\text {max }},
$$

with $k_{\max }=T_{\text {acq }} \times f_{\text {mains }}$. This value is independent from the sampling frequency used to sample the current itself, $f_{\text {sampling }}$. Comparing (11) and (15), the rate of reduction of the number of data points that must be stored and processed is

$$
\frac{k_{\max }}{N_{\max }}=\frac{f_{\text {mains }}}{f_{\text {sampling }}} \text {. }
$$

In the case of the $3.15 \mathrm{MW}$ motor, the proposed approach represents a rate of reduction of $50 / 5 \times 10^{3}=1 / 100$. The reduced envelope of the current of this motor, $i_{\text {red_env_faulty }}(t)$, is presented in Fig. 7, and the spectrum of $i_{\text {red_env_faulty }}(t)$ is presented in Fig. 8.

Although the number of points used for computing the spectrum of the reduced envelope $i_{\text {red_env_faulty }}(t)$ (4997 data points) has been reduced by a factor of 100 compared with the spectrum obtained from the full length current envelope, 


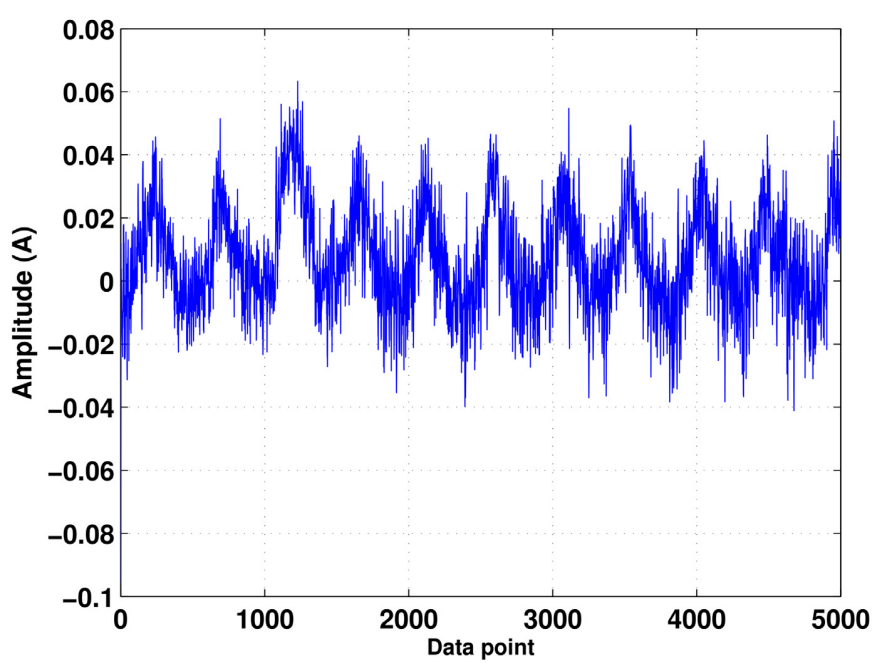

Fig. 7. The proposed diagnostic quantity: reduced envelope of the stator current $i_{\text {red_env_faulty }}(t)$ of the $3.15 \mathrm{MW}$ motor with one broken bar.

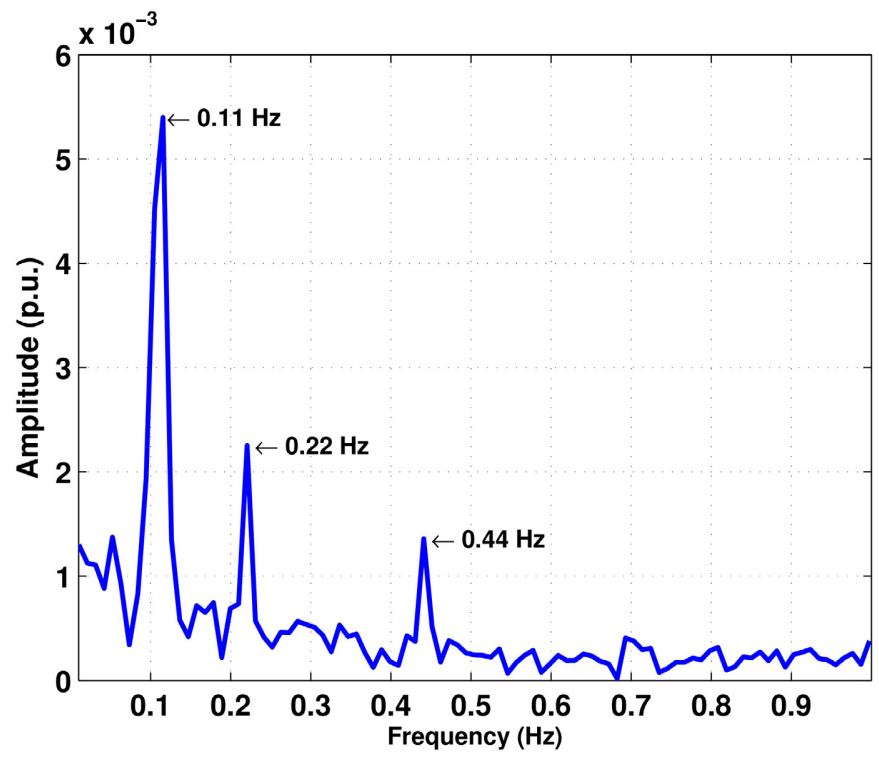

Fig. 8. FFT of the reduced current envelope $i_{\text {red_env_faulty }}(t)$ of the 3.15 MW motor with one broken bar (4997 data points).

$i_{\text {env_faulty }}(t)$, shown in Fig. $4\left(5 \times 10^{5}\right.$ data points), all the fault harmonics can be clearly identified. The coincidence of the spectra presented in Fig. 4 and in Fig. 8 is not casual, since both spectra correspond to the same signal (the AC component of the current envelope), although sampled at different frequencies. In any case, the sampling frequencies of both signals $i_{\text {env_faulty }}(t)$ and $i_{\text {red_env_faulty }}(t)$ is much higher than the frequencies of the fault components, which justifies the coincidence of their spectra in the range of frequencies analysed (below $1 \mathrm{~Hz}$ ).

\section{A. Practical implementation of the proposed method}

From a computing point of view, the proposed signal $i_{\text {red_env_faulty }}(t)$ is built using only the samples of the current taken at the crossings with the real axis of the AS of the current, (12). But, from (6), this condition is met at the positive zero crossings of the imaginary part of the AS, the Hilbert transform of the current $\mathcal{H}\left(i_{\text {faulty }}\right)(t)$, so that (12) becomes

$$
\left|\vec{i}_{\text {faulty }}(t)\right|_{\theta(t)=2 k \pi}=\left.i_{\text {faulty }}(t)\right|_{\mathcal{H}\left(i_{\text {faulty }}\right)(t)=0} .
$$

The implementation of (17) is shown in Fig. 9. A very high sampling frequency $f_{\text {sampling }}$ can be used by a DSP or a FPGA to precisely locate the zero crossings of $\mathcal{H}\left(i_{\text {faulty }}\right)(t)$, because the number of data points used to compute the FFT does not scale with $f_{\text {sampling, }}$, but remains proportional to $f_{\text {mains }}$.

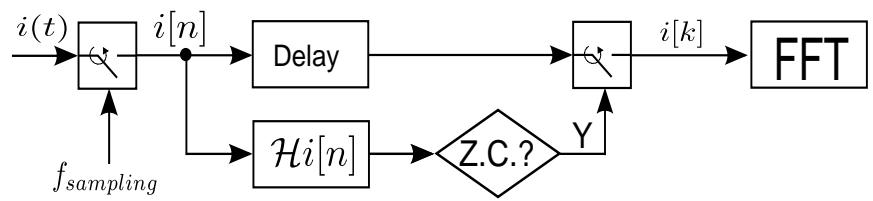

Fig. 9. Practical way of computing the proposed diagnostic quantity $i[k]$, by downsampling the current $i[n]$ at the positive zero crossings (Z.C.) of its Hilbert transform $\mathcal{H}(i)[n]$.

In this paper, both the Hilbert transformer and the delay unit of Fig. 9 have been implemented with a single linearphase equiripple filter, whose discrete finite impulse response (FIR) structure is shown in Fig. 10.

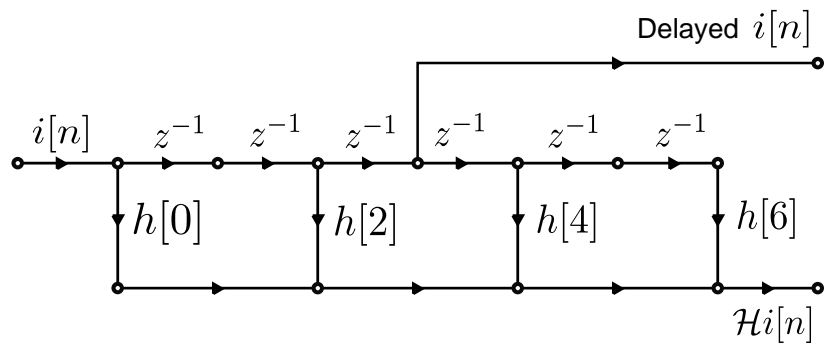

Fig. 10. Example of implementation of the delay and the Hilbert transform of the sampled current using a 7-tap FIR Hilbert filter. The actual filter used in the paper is a 31-tap filter.

The actual filter used in this work has an order of 30 , a transition width of $0.2 \pi$, and has a reduced cost both in terms of storage (just 30 values) and computing power (16 multiplications and 16 additions per sample), so that it can be implemented on very simple devices. The impulse response of this filter is shown in Fig. 11, where it can be seen that the even coefficients of the filter have a zero value, which simplifies even more its implementation.

\section{EXPERIMENTAL VALIDATION OF THE PROPOSED METHOD}

An experimental validation of the proposed method has been carried out in Section IV, where the proposed method is applied to the direct line fed, high power, high voltage motor working in actual conditions, which was presented in the case study of section II; in this type of IM is where a broken bar fault is more likely to occur. To perform a further experimental validation, in this section, the proposed method is applied under laboratory conditions to a commercial motor, 


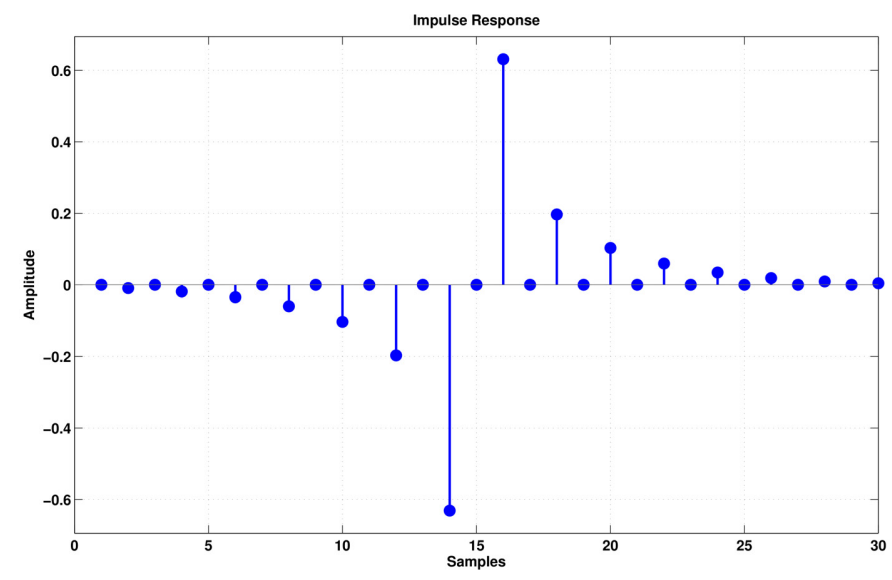

Fig. 11. Impulse response of the Hilbert filter of order 30 used in this work.

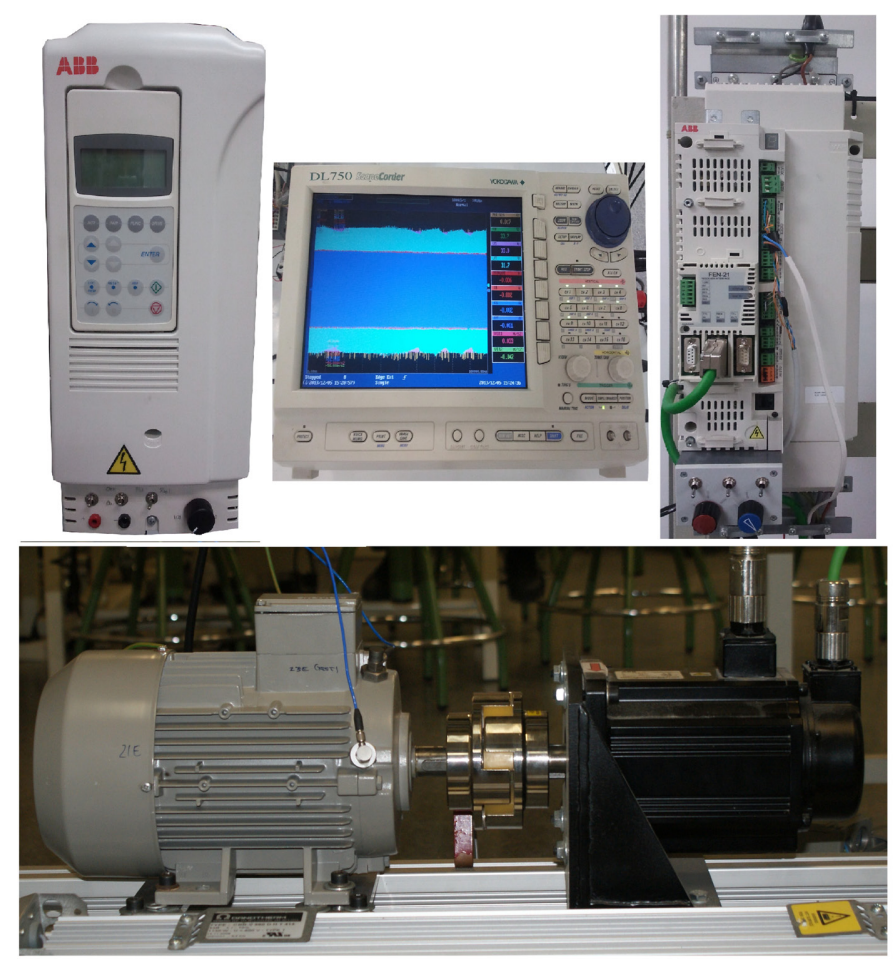

Fig. 12. Test bench. Bottom, cage motor coupled to a permanent magnet synchronous machine. Top, VSD (left), servo driver (right) and digital oscilloscope (center)

whose characteristics are given in Appendix A (Motor type II), using the test bench depicted in Fig. 12.

The motor under test is fed through a VSD, shown in Fig. 12, left (ABB ACS800-01-0005-3). The mechanical load is obtained through the use of a permanent magnet synchronous machine (PMSM), controlled by a servo driver shown in Fig. 12, right (ABB ACSM1-04AS-024A-4). A bar of the motor has been broken by drilling a hole at the end of the bar, as can be seen in Fig. 13.

The current has been sampled during 10 seconds with a sampling rate of $50 \mathrm{kHz}$, giving a total of $5 \times 10^{5}$ current samples. The switching frequency of the inverter has been established in $2 \mathrm{kHz}$, the predefined value. Although it can be

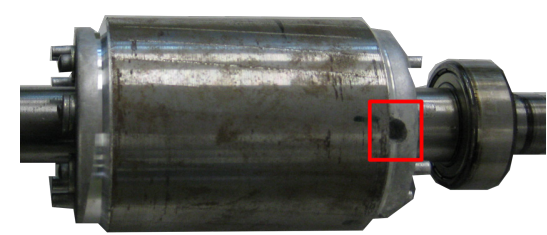

Fig. 13. Rotor with a forced broken bar.

adjusted by the user, it is far enough from the frequencies of interest for fault diagnosis and it was not necessary to change this value. Besides, to avoid the high frequencies generated by the VSD, the current has been filtered digitally with a wavelet filter, using a Daubechies-44 mother wavelet, and taking the approximation signal of level 9 of the discrete wavelet transform. The behaviour of the proposed method against the control method used in the VSD (CV/F or DTC, as in [38]) has been tested with this motor. Furthermore, as the validity of the method at rated frequency has been demonstrated in the theoretical explanation and in the case of study, in the following tests (inverter-fed tests) the IM has been tested at lower frequencies to prove also its validity under these conditions, usual in the case of inverted-fed induction motors. The use of both control methods CV/F (open-loop) and DTC (close-loop) has been considered of interest due to the fact that, as [34] points out, close-loop controls damps the speed variations due to the fault $(2 s f)$, unlike open-loop controls. Anyway, regardless of the control method, the electromagnetic fault component always appears in the spectrum of the current and in the spectrum of the current envelope.

In the first test, the VSD has been used in CV/F mode, at $25 \mathrm{~Hz}$, with the motor running without any external load (just the PMSM mechanical losses), at a speed of $1497 \mathrm{rpm}$. The results of this test are depicted in Fig. 14.

In the second test, the VSD has been operated in DTC mode, with a reference speed of $1500 \mathrm{rpm}$, and with the motor loaded at $70 \%$ of its rated load (actual output frequency $26.7 \mathrm{~Hz}$ ). The results of this test are depicted in Fig. 15. The percentage of load has been adjusted using the torque control available in the servodriver which controls the PMSM. This load level has been established as the percentage of the rated load of the IM.

The results presented in Fig. 14 and Fig. 15 are the following ones: first, both the motor current and its envelope are represented (Fig. 14.a and Fig. 15.a). The spectrum of the current $i_{\text {faulty }}(t)$ (Fig. 14.b and Fig. 15. b), and the spectrum of the current envelope $i_{\text {env_faulty }}(t)$ (Fig. 14.c and Fig. 15.c) are shown to assess the presence of the fault. Both spectra make use of the full amount of current samples $\left(5 \times 10^{5}\right.$ data points). Next, the proposed diagnostic quantity, the reduced envelope of the stator current $i_{\text {red_env_faulty }}(\mathrm{t})$, is built with a very small number of samples of the motor current (250 in Fig. 14.d and 267 in Fig. 15.d). These current samples are taken at the positive zero crossings of the Hilbert transform of the current, following the procedure depicted in Fig. 9. It is remarkable that in both tested cases, the spectrum of this quantity, shown in Fig. 14.e and Fig. 15.e, practically coincides with the spectrum of the conventional full length 
a)
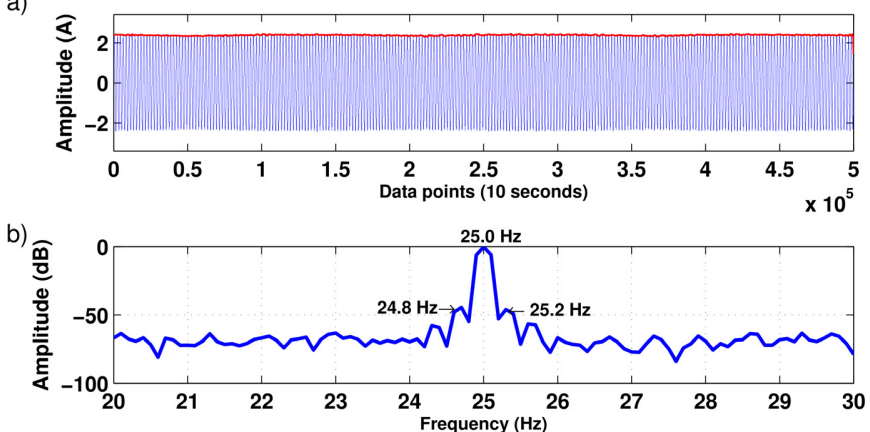

c)

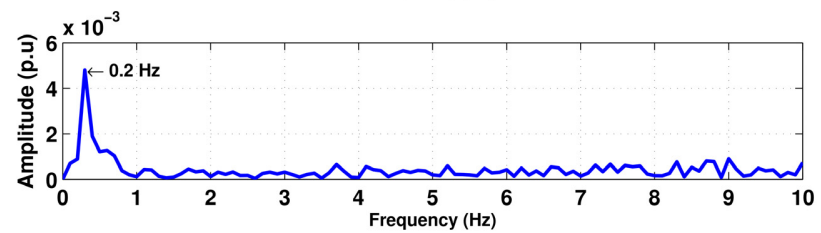

d)

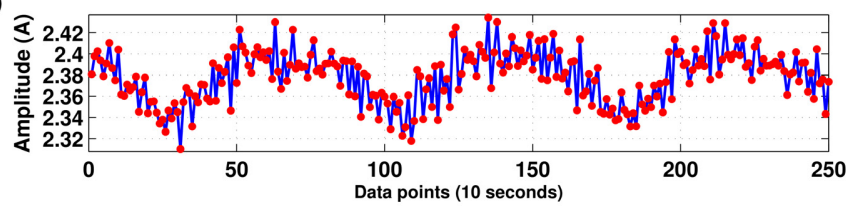

e)

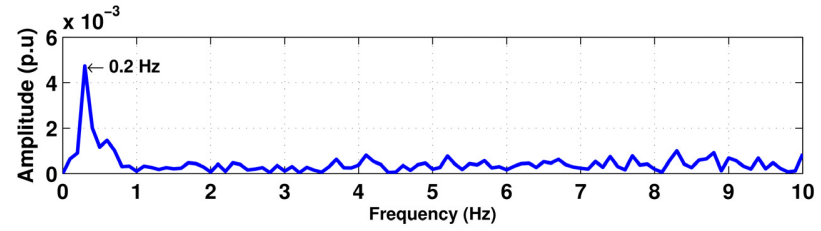

Fig. 14. Motor with one broken bar fed from a VSD in constant voltage per frequency $(\mathrm{CV} / \mathrm{F})$ mode, at low load. (a) Motor current (thin, blue line) and its envelope (thick, red line), with $5 \times 10^{5}$ samples. (b) Spectrum of the current $i_{\text {faulty }}(t)$. (c) Spectrum of the current envelope $i_{\text {env_faulty }}(t)$. (d) Reduced envelope of the motor current $i_{\text {red_env_faulty }}(t)$, with 250 samples. (e) Spectrum of the reduced envelope of the stator current.

current envelope, shown in Fig. 14.c and Fig. 15.c respectively, although it has been obtained using the FFT of a minimal fraction of the total number of current samples. These results corroborate those obtained with the high voltage motor (see Fig. 4 and Fig. 8). Besides, the computation of the modulus of the AS current (8), used to build the traditional current envelope $i_{\text {env_faulty }}(t)$, has not been used at all for assembling the proposed diagnostic signal $i_{\text {red_env_faulty }}(t)$.

\section{COMPARATIVE ANALYSIS}

This section presents a comparative analysis between the results obtained with the full-length envelope of the current and the results obtained with the new signal proposed in this paper (the reduced envelope), using the three test cases presented in previous sections. This comparison has been developed using the computer whose main features are shown in Appendix B. Case 1 is the test presented in Section II, a high power induction machine (see Fig. 4 and Fig. 8). Case 2 and case 3 are the tests presented in Section V, using a low power, inverter-fed commercial IM, both in CV/F control mode (case 2, Fig. 14) and in DTC control mode (case 3, Fig. 15). The features compared, computation time and memory usage,
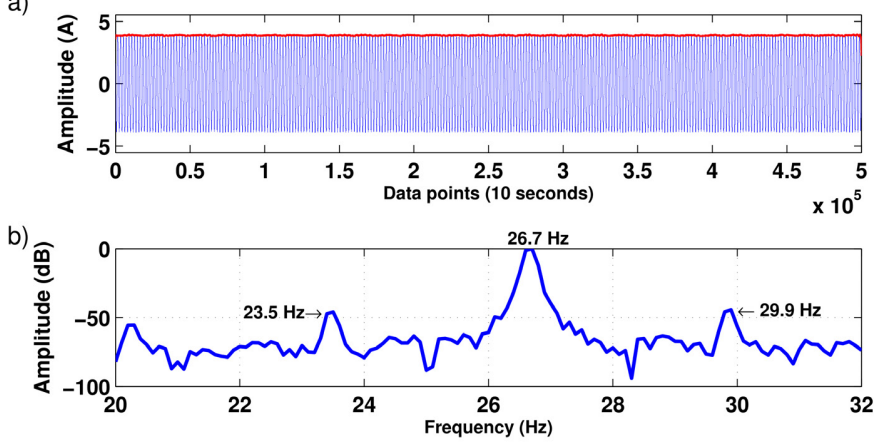

c)

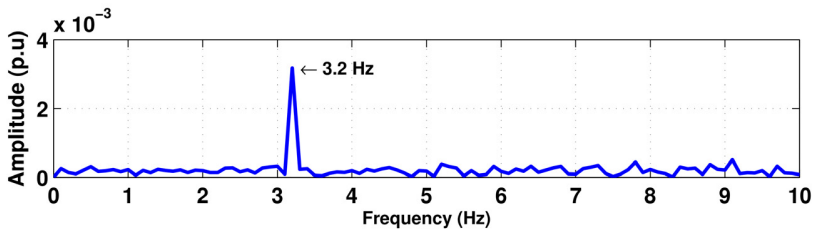

d)

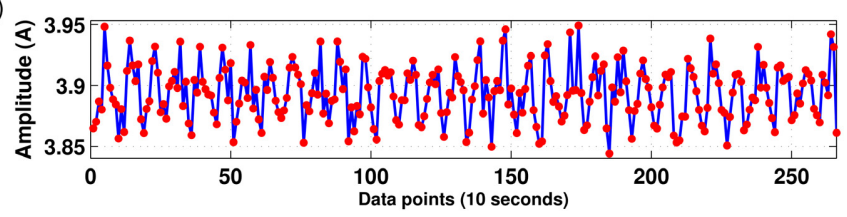

e)

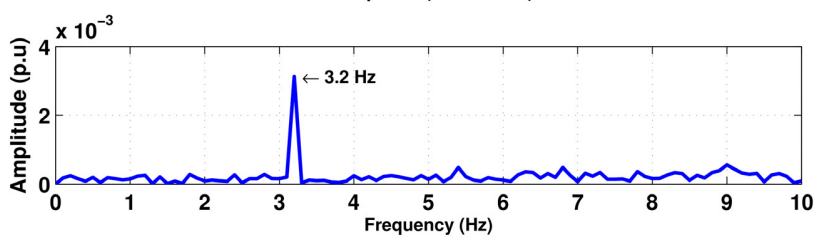

Fig. 15. Motor with one broken bar fed from a VSD in DTC mode, at medium load. (a) Motor current (thin, blue line) and its envelope (thick, red line), with $5 \times 10^{5}$ samples. (b) Spectrum of the current. (c) Spectrum of the current envelope. $i_{\text {env_faulty }}(t)$. (d) Reduced envelope of the motor current $i_{\text {red_env_faulty }}(t)$, with 267 samples. (e) Spectrum of the reduced envelope of the stator current.

are critical for the use of low cost electronic devices in on-line diagnostic systems. In all the tested cases the differences in the amplitude of the most significant fault component, computed using the proposed signal and the full-length current envelope, are also reported. The comparisons are given in Table I (computation time needed to obtain the current envelope spectrum), in Table II (amount of memory needed to store the current envelope) and in Table III (differences in the amplitude of the most significant fault component).

The results presented in Table I and in Table II show reduction rates of several orders of magnitude both in computation time and memory usage using the proposed method, compared with the full length current envelope. Despite this great reduction in computing resources, both methods achieve the same accuracy, as shown in Table III, and also in figures 4, 8, 14.c, 14.e, 15.c and 15.e. These features make the proposed technique especially well suited for implementing the diagnostic system on low cost devices, and even on the same device that controls the power electronics of the VSD, without disturbing its normal operation. 
TABLE I

COMPARISON OF THE COMPUTATION TIME NEEDED TO OBTAIN THE CURRENT ENVELOPE SPECTRUM

\begin{tabular}{lccc}
\hline \hline & \multicolumn{2}{c}{ Computation time (ms) } & Reduction \\
& (A) Reduced envelope & (B) Full envelope & A/B (\%) \\
\hline Case 1 & 1.082 & 48.141 & 2.24 \\
Case 2 & 0.085 & 41.587 & 0.20 \\
Case 3 & 0.142 & 41.607 & 0.34 \\
\hline \hline
\end{tabular}

TABLE II

COMPARISON OF THE AMOUNT OF MEMORY NEEDED TO STORE THE CURRENT ENVELOPE

\begin{tabular}{lccc}
\hline \hline & \multicolumn{2}{c}{ Memory size (kB) } & Reduction \\
& (A) Reduced envelope & (B) Full envelope & A/B (\%) \\
\hline Case 1 & 35 & 3737 & 0.94 \\
Case 2 & 3 & 3603 & 0.08 \\
Case 3 & 3 & 3686 & 0.08 \\
\hline \hline
\end{tabular}

\section{CONCLUSIONS}

In this paper a novel method for the fault diagnosis of induction motors has been presented, based on the analysis of a new diagnostic quantity, the reduced envelope of the stator current. The proposed method improves the present on-line diagnostic methods of IMs working at a very low slip, because it allows that low cost diagnostic devices can use, simultaneously, a high sampling rate, to reduce the complexity of anti-aliasing hardware filters, and a long acquisition time, to achieve a high spectral resolution. Furthermore, the proposed method converts the mains component into a DC value, which avoids the use of notch filters. And all these features are achieved storing an extremely small amount of current samples, just one per cycle, and, at the same time, eliminating the costly process of computing the modulus the AS of the current. Hence, both features make the proposed method specially well suited for its implementation on low cost on-line devices. The key of the proposed method is the generation of the proposed diagnostic signal by downsampling the current signal at the positive zero crossings of its HT, implemented using a very short Hilbert transformer. This approach preserves the fault information contained in the original current signal, but at a fraction of the cost associated to processing the full length signal, in terms of storage and computing resources.

The proposed method has been validated with a large $3.15 \mathrm{MW}$ motor, and also with a small $1.5 \mathrm{~kW}$ commercial motor fed with a VSD, operating in CV/F and DTC mode. Reduction rates of several orders of magnitude have been achieved in the number of stored current samples, computation time and memory usage, while maintaining the same capacity of fault detection and identification that is achieved using the full set of current samples.
TABLE III

COMPARISON OF THE AMPLITUDES OF THE MOST SIGNIFICANT FAULT COMPONENT

\begin{tabular}{lccc}
\hline \hline & \multicolumn{2}{c}{ Amplitude of the fault component (p.u.) } & Difference \\
& (A) Reduced envelope & (B) Full envelope & $($ A-B)/B (\%) \\
\hline Case 1 & $5.401 \cdot 10^{-3}$ & $5.326 \cdot 10^{-3}$ & 1.39 \\
Case 2 & $4.729 \cdot 10^{-3}$ & $4.802 \cdot 10^{-3}$ & 1.48 \\
Case 3 & $3.128 \cdot 10^{-3}$ & $3.173 \cdot 10^{-3}$ & 1.42 \\
\hline \hline
\end{tabular}

\section{APPENDIX A \\ INDUCTION MACHINES' CHARACTERISTICS}

Motor type I: three-phase induction motor, star connection. Rated characteristics: $P=3150 \mathrm{~kW}, f=50 \mathrm{~Hz}$, $U=6 \mathrm{kV}, I=373 \mathrm{~A}, n=2982 \mathrm{rpm}$, and $\cos \varphi=0.92$.

Motor type II: three-phase induction motor, star connection. Rated characteristics: $P=1.5 \mathrm{~kW}, f=50 \mathrm{~Hz}$, $U=400 \mathrm{~V}, I=3.25 \mathrm{~A}, n=2860 \mathrm{rpm}$, and $\cos \varphi=0.85$.

\section{APPENDIX B COMPUTER FEATURES}

CPU: Intel Core i7-2600K CPU @ 3.40 GHZ RAM memory: $16 \mathrm{~GB}$, Matlab Version: 8.0.0.783 (R2012b)

\section{REFERENCES}

[1] L. Saidi, F. Fnaiech, H. Henao, G. Capolino, and G. Cirrincione, "Diagnosis of broken-bars fault in induction machines using higher order spectral analysis," ISA Transactions, vol. 52, no. 1, pp. 140-148, 2013.

[2] B. Ayhan, H. Trussell, M. Y. Chow, and M. H. Song, "On the Use of a Lower Sampling Rate for Broken Rotor Bar Detection With DTFT and AR-Based Spectrum Methods," IEEE Trans. Ind. Electron., vol. 55, no. 3, pp. 1421-1434, March 2008.

[3] I. Tsoumas, G. Georgoulas, E. Mitronikas, and A. Safacas, "Asynchronous Machine Rotor Fault Diagnosis Technique Using Complex Wavelets," IEEE Trans. Energy. Convers., vol. 23, no. 2, pp. 444-459, 2008.

[4] S. Kia, H. Henao, and G. A. Capolino, "Diagnosis of Broken-Bar Fault in Induction Machines Using Discrete Wavelet Transform Without Slip Estimation," IEEE Trans. Ind. Appl., vol. 45, no. 4, pp. 1395-1404, 2009.

[5] D. Matic, F. Kulic, M. Pineda-Sanchez, and I. Kamenko, "Support vector machine classifier for diagnosis in electrical machines: Application to broken bar,' Expert Systems with Applications, vol. 39, no. 10, pp. 86818689, 2012.

[6] R. Puche-Panadero, M. Pineda-Sanchez, M. Riera-Guasp, J. RogerFolch, E. Hurtado-Perez, and J. Perez-Cruz, "Improved Resolution of the MCSA Method Via Hilbert Transform, Enabling the Diagnosis of Rotor Asymmetries at Very Low Slip," IEEE Trans. Energy. Convers., vol. 24, no. 1, pp. 52-59, 2009.

[7] B. Xu, L. Sun, L. Xu, and G. Xu, "Improvement of the Hilbert Method via ESPRIT for Detecting Rotor Fault in Induction Motors at Low Slip," IEEE Trans. Energy. Convers., vol. 28, no. 1, pp. 225-233, 2013.

[8] H. Çaliş and A. Çakir, "Experimental study for sensorless broken bar detection in induction motors," Energy Conversion and Management, vol. 49, no. 4, pp. 854-862, 2008.

[9] M. Cabanas, F. Pedrayes, C. Rojas, M. Melero, J. Norniella, G. Orcajo, J. Cano, F. Nuno, and D. Fuentes, "A New Portable, Self-Powered, and Wireless Instrument for the Early Detection of Broken Rotor Bars in Induction Motors," IEEE Trans. Ind. Electron., vol. 58, no. 10, pp. 4917-4930, 2011.

[10] A. Bellini, "Quad Demodulation: A Time-Domain Diagnostic Method for Induction Machines," IEEE Trans. Ind. Appl., vol. 45, no. 2, pp. 712-719, 2009.

[11] B. Akin, S. Choi, U. Orguner, and H. Toliyat, "A Simple Real-Time Fault Signature Monitoring Tool for Motor-Drive-Embedded Fault Diagnosis Systems," IEEE Trans. Ind. Electron., vol. 58, no. 5, pp. 1990-2001, 2011. 
[12] G. Joksimovic, J. Riger, T. Wolbank, N. Peric, and M. Vasak, "StatorCurrent Spectrum Signature of Healthy Cage Rotor Induction Machines," IEEE Trans. Ind. Electron., vol. 60, no. 9, pp. 4025-4033, 2013.

[13] A. Yazidi, H. Henao, G. A. Capolino, F. Betin, and F. Filippetti, "A Web-Based Remote Laboratory for Monitoring and Diagnosis of AC Electrical Machines," IEEE Trans. Ind. Electron., vol. 58, no. 10, pp. 4950-4959, 2011.

[14] X. Gong and W. Qiao, "Bearing Fault Diagnosis for Direct-Drive Wind Turbines via Current-Demodulated Signals," IEEE Trans. Ind. Electron., vol. 60, no. 8, pp. 3419-3428, 2013.

[15] S. Choi, B. Akin, M. Rahimian, and H. Toliyat, "Implementation of a Fault-Diagnosis Algorithm for Induction Machines Based on Advanced Digital-Signal-Processing Techniques," IEEE Trans. Ind. Electron., vol. 58, no. 3, pp. 937-948, 2011.

[16] S. Kia, H. Henao, and G. Capolino, "A High-Resolution Frequency Estimation Method for Three-Phase Induction Machine Fault Detection,' IEEE Trans. Ind. Electron., vol. 54, no. 4, pp. 2305-2314, 2007.

[17] K. Yong-Hwa, Y. Young-Woo, H. Don-Ha, S. Jong-Ho, and K. DongSik, "High-Resolution Parameter Estimation Method to Identify Broken Rotor Bar Faults in Induction Motors," IEEE Trans. Ind. Electron. vol. 60, no. 9, pp. 4103-4117, 2013.

[18] B. Xu, L. Sun, L. Xu, and G. Xu, "An ESPRIT-SAA-Based Detection Method for Broken Rotor Bar Fault in Induction Motors," IEEE Trans. Energy. Convers., vol. 27, no. 3, pp. 654-660, 2012.

[19] I. Georgakopoulos, E. Mitronikas, and A. Safacas, "Detection of Induction Motor Faults in Inverter Drives Using Inverter Input Current Analysis," IEEE Trans. Ind. Electron., vol. 58, no. 9, pp. 4365-4373, 2011.

[20] S. B. Salem, K. Bacha, and A. Chaari, "Support vector machine based decision for mechanical fault condition monitoring in induction motor using an advanced Hilbert-Park transform," ISA Transactions, vol. 51, no. 5, pp. 566-572, 2012

[21] R. Romero-Troncoso, R. Saucedo-Gallaga, E. Cabal-Yepez, A. GarciaPerez, R. Osornio-Rios, R. Alvarez-Salas, H. Miranda-Vidales, and N. Huber, "FPGA-Based Online Detection of Multiple Combined Faults in Induction Motors Through Information Entropy and Fuzzy Inference,' IEEE Trans. Ind. Electron., vol. 58, no. 11, pp. 5263-5270, 2011.

[22] S. Toscani, M. Faifer, M. Rossi, L. Cristaldi, and M. Lazzaroni, "Effects of the Speed Loop on the Diagnosis of Rotor Faults in Induction Machines," IEEE Trans. Instrum. Meas., vol. 61, no. 10, pp. 2713-2722, 2012.

[23] A. Soualhi, G. Clerc, and H. Razik, "Detection and Diagnosis of Faults in Induction Motor Using an Improved Artificial Ant Clustering Technique," IEEE Trans. Ind. Electron., vol. 60, no. 9, pp. 4053-4062, 2013.

[24] K. Shahzad, P. Cheng, and B. Oelmann, "Architecture Exploration for a High-Performance and Low-Power Wireless Vibration Analyzer," IEEE Sensors J., vol. 13, no. 2, pp. 670-682, 2013.

[25] R. Sharifi and M. Ebrahimi, "Detection of stator winding faults in induction motors using three-phase current monitoring," ISA Transactions, vol. 50, no. 1, pp. 14-20, 2011.

[26] A. Lebaroud and A. Medoued, "Online computational tools dedicated to the detection of induction machine faults," International Journal of Electrical Power \& Energy Systems, vol. 44, no. 1, pp. 752 - 757, 2013.

[27] A. Garcia-Perez, R. de Jesus Romero-Troncoso, E. Cabal-Yepez, and R. A. Osornio-Rios, "The Application of High-Resolution Spectral Analysis for Identifying Multiple Combined Faults in Induction Motors," IEEE Trans. Ind. Electron., vol. 58, no. 5, pp. 2002-2010, 2011.

[28] A. Ceban, R. Pusca, and R. Romary, "Study of Rotor Faults in Induction Motors Using External Magnetic Field Analysis," IEEE Trans. Ind. Electron., vol. 59, no. 5, pp. 2082-2093, 2012.

[29] P. Vaclavek, P. Blaha, and I. Herman, "AC Drive Observability Analysis," IEEE Trans. Ind. Electron., vol. 60, no. 8, pp. 3047-3059, 2013

[30] D. J. White, P. E. William, M. W. Hoffman, and S. Balkir, "Low-Power Analog Processing for Sensing Applications: Low-Frequency Harmonic Signal Classification," Sensors, vol. 13, no. 8, pp. 9604-9623, 2013.

[31] N. Freire, J. Estima, and A. Cardoso, "A New Approach for Current Sensor Fault Diagnosis in PMSG Drives for Wind Energy Conversion Systems," IEEE Trans. Ind. Appl., vol. 50, no. 2, pp. 1206-1214, March 2014.

[32] T. Wolbank, P. Nussbaumer, H. Chen, and P. Macheiner, "Monitoring of Rotor-Bar Defects in Inverter-Fed Induction Machines at Zero Load and Speed," IEEE Trans. Ind. Electron., vol. 58, no. 5, pp. 1468-1478, 2011.

[33] J. Faiz, V. Ghorbanian, and B. Ebrahimi, "EMD-Based Analysis of Industrial Induction Motors With Broken Rotor Bars for Identification of
Operating Point at Different Supply Modes," IEEE Trans. Ind. Informat., vol. 10, no. 2, pp. 957-966, May 2014.

[34] V. Ghorbanian and J. Faiz, "A survey on time and frequency characteristics of induction motors with broken rotor bars in line-start and inverter-fed modes ," Mechanical Systems and Signal Processing, vol. 54, pp.427-456, 2015.

[35] A. da Silva, R. Povinelli, and N. Demerdash, "Induction Machine Broken Bar and Stator Short-Circuit Fault Diagnostics Based on Three-Phase Stator Current Envelopes," IEEE Trans. Ind. Electron., vol. 55, no. 3, pp. 1310-1318, March 2008.

[36] W. Jinjiang, L. Shaopeng, X. Robert, and Y. Ruqiang, "Current envelope analysis for defect identification and diagnosis in induction motors ,' Journal of Manufacturing Systems , vol. 31, no. 4, pp. 380-387, 2012.

[37] B. Zhang, C. Sconyers, C. Byington, R. Patrick, M. Orchard, and G. Vachtsevanos, "A Probabilistic Fault Detection Approach: Application to Bearing Fault Detection," IEEE Trans. Ind. Electron., vol. 58, no. 5, pp. 2011-2018, 2011.

[38] J. Faiz and M. Ojaghi, "Stator Inductance Fluctuation of Induction Motor as an Eccentricity Fault Index," IEEE Trans. Magn., vol. 47, no. 6, pp. $1775-1785,2011$

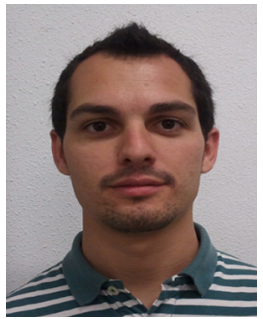

Angel Sapena-Baño obtained its M.Sc. degree in 2009 and his $P h$. D. degree in 2014 from the Universitat Politecnica de Valencia (Spain) both in Electrical Engineering. From 2008 he works as a Researcher in the Institute for Energy Engineering of Universitat Politecnica de Valencia. His research interests focus on induction motor diagnostics and the maintenance based on the condition monitoring, numerical modelling of electrical machines, and advanced automation processes and electrical installations.

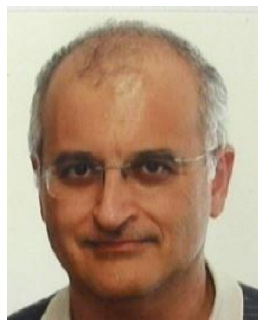

Manuel Pineda-Sanchez (M02) received his M.Sc. degree in 1985 and his Ph.D. degree in 2004 from the Universitat Politecnica de Valencia, both in Electrical Engineering. Currently he is an Associate Professor with the Department of Electrical Engineering of the Universitat Politecnica de Valencia. His research interests include electrical machines and drives, induction motor diagnostics, and numerical simulation of electromagnetic fields.

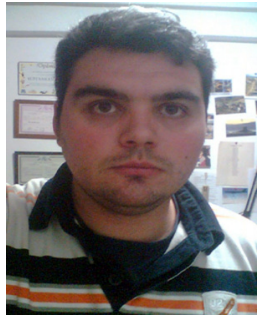

Ruben Puche-Panadero (M09) received his M.Sc. degree in Automatic and Electronic Engineering in 2003, and its Ph.D. degree in Electrical Engineering in 2008, both from the Universitat Politecnica de Valencia. He joined the Universitat Politecnica de Valencia in 2006 and he is currently Associate Professor of Control of Electrical Machines. His research interests focus on induction motor diagnosis, numerical modeling of electrical machines, and advanced automation processes and electrical installations.

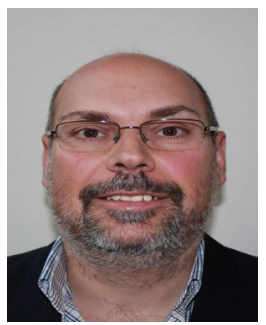

Javier Martínez-Román was born in 1965 . He received the Ph.D. degree in Electrical Engineering from the Polytechnic University of Valencia, Spain, in 2002. Currently he is Associate Professor with the Universidad Politcnica de Valencia. His primary areas of interest are electrical machines and drives. He has participated in various international projects supported by the European Union. He has published several papers on electrical machines in international journals and conference proceedings.

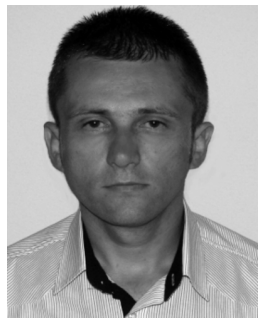

Željko Kanović was born on July 18th, 1976, in Sombor, Serbia. He received the B.Sc. degree in Mechanical Engineering in 2000, and the M.Sc. and Ph.D. degree in Electrical Engineering in 2007 and 2012, all from the University of Novi Sad, Serbia. Currently, he is Assistant Professor at the Computing and Control Department at the same University. His research interest is in the field of global optimization and its application in control, modeling, fault detection, artificial intelligence and engineering design. 